\title{
Physical Fitness of the Doctor: Hypocrisy
}

\author{
William D. Stannish MD FRCSC FACS
}

This opinion piece was originally published in DMJ, Winter 1969. Accompanying it are two contemporary accounts of health professionals' initiatives to promote exercise and improve community health.

How frequently has it been said to the patient by the average practicing physician while he lounges behind his pretentious solid oak antique desk, fumbling with his Export-A King-size, with vulgar obesity camouflaging his authentic alligator belt: "Mr. Jones, you will certainly have to eat far less, stop smoking, and get plenty of exercise." What right does the doctor possess that allows him to offer this apparently sound advice to the lay public and then feel quite justified in becoming acutely hypertensive when the patient does not follow the prescribed therapeutic regime? In my opinion, it is like all types of advertising in this affluent society of ours; the most qualified person to sell hockey sticks, is a hockey player, who uses that particular stick; the most qualified individual to advocate a certain scotch whiskey is a well-known connoisseur, who indulges in that particular brand; and, the most qualified person to advocate personal exercise and denounce the dangers of tobacco, as well as excessive food and drink, is the apparently knowledgeable doctor!

As a medical student, the individual becomes unbelievably preoccupied with the demands that his profession will eventually place upon him and thus, never allows himself the opportunity to indulge in excesses that will certainly enhance his entire state of wellbeing except for the infrequent euphoria induced by alcohol. To my way of thinking, the problem of lack of emphasis on physical fitness of medical personnel, originates in the medical school but this same lack of emphasis continues to be propagated throughout the realm of the graduate doctor, also. How often in defense have I heard this statement "Why, I am in pretty good shape. I golf." What nonsense! How many doctors, or future doctors, can honestly state that at one time they have been in the best physical condition that they personally are capable of achieving? Unbelievably few! Physical fitness is a subjective phenomenon. In order to fully appreciate this sensation, it is essential that the individuals have been in excellent physical condition at one time in his life and it is also equally as essential that these same individuals have been in atrocious condition at another time. The importance of possessing this vivid contrast cannot be over-emphasized because the tremendous value one absorbs from physical fitness takes on new magnitude in light of having functioned in a relatively inefficient, languid atonic physical state.

In medicine, subjects which cultivate controversy are reviewed with skepticism and invariably the question is posed, "Well, what references back up your statements?" If one is unable to supply a prolonged list of so-called world authorities, the controversial issue is resolved without question or any further discussion. Physical fitness falls in the category of a controversial issue. The question, "Why should I be physically fit?" can be answered by quoting multiple international research programs conducted to ascertain whether physical fitness inhibits atherosclerosis, if physical fitness increases maximum voluntary ventilation and so on. In my opinion, this logical approach is absolutely absurd because, to me, physical conditioning is a subjective state and should remain unthreatened by tedious statistics and esoteric data. In the same vein that I advocate cigarette smoking for people who really enjoy it, I preach physical exercise and fitness hoping to achieve enjoyment alone. The beneficial effects to the anatomy of the cardiovascular system, respiratory system, and musculoskeletal structures should be fringe benefits only.

During the era of the Greeks and Romans, emphasis of the social was directed towards the development of the "complete man." This individual was a great intellect, able to comprehend politics and philosophy, able to absorb himself in the arts, able to ponder the fate of the universe, and, most important, able to participate and compete athletically. Authorities speak of this specific era in history as perhaps the most sophisticated and progressive ever. Why must we in the medical community of the 20th century be burdened by the compulsive trends toward not only achieving an undefinable goal but killing ourselves in the process without really taking any time to enjoy it?

To allow oneself the time (what an almighty word) to romp in the local gymnasium, on the football field or park, will probably induce more than a meager sweat and severe dyspnea but will ultimately convince 
the average doctor that these are manifestations of relaxation, not congestive heart failure. Too frequently, as medical personnel, we procrastinate because we are either too lazy in this regard to exert ourselves or we have achieved such poor physical condition that our bodies will no longer perform on command; the former assertion usually prevails. How then, shall we motivate ourselves?

The majority of individuals in our society mechanically pursue routine daily activities without pondering "Why am I doing this?" and "What do I hope to achieve, if anything?" The factors which motivate people to pursue goals are highly variable and certainly fluctuate from one individual to the next. No exception to this rule is the devotee to physical fitness. What motivates him to want to achieve a sound, healthy physical state? This is a goal that, in order to be attained, the individual must, at some time, experience the physical pain of full exertion. Thus, the source of motivation must be solidly engrained in the individual or the project will be doomed to failure or will yield less than ideal results.

The majority of doctors are driven by the incessant fear of falling into the trap which consumed their colleagues en masse: that is, the trap of myocardial infarction and/ or debilitating hypertension. Does this doctor, who is motivated by fear alone to run one mile every two weeks, get full-benefit from his exercise? That is somewhat similar to having an elective surgical procedure in contrast to an emergency surgical effort in which the prognosis is generally dim. In only seems reasonable that the doctor that exercises regularly because he enjoys the experience will reap greater dividend than the doctor who drives his body irregularly, usually the day after a fellow practitioner has had an abrupt heart attack. The former doctor is usually one who enjoys the general state of wellbeing he develops partaking in a regular physical fitness program. He is the same individual who discovers his efficiency and versatility as a doctor, family man, community leader and partygoer are enhanced tremendously by his state of physical fitness.

Doctors are exposed to relentless social pressures in our social system and thus it follows that the motivating impetus for some doctors to participate in fitness programs is because their social circle demands this role. It may be Sunday golf game or curling match but the fact remains that, if that individual doctor was allowed to exercise his prerogative, he would no doubt pass up the physical activity to catch up on some less strenuous work. There are certainly doctors who belong to local golf clubs not because they wish to exploit the facilities but because it is compatible with a role image that they feel they must pursue. What adds insult to the situation is that doctors that do play golf feel they are getting sufficient exercise from the activity to be categorized as physically fit.

What is the remedy to this horrible situation? What should be the ideal motivating factor? I do not feel there is a single remedy or an ideal prime motivating force, as long as the individual is enjoying a physical activity without fear of the consequences, which could prevail if he was not indulging in that program. If the exercise regime that the doctor is involved in provides him with some feeling, some functional gain or some exertion that he ordinarily would not experience, then the program must be deemed successful.

The Medical Fraternity is geared towards the maximum exploitation of every minute of every day. It generally follows that the doctor's life passes him by before he has time to live it and, most important, to enjoy it. As medical students, we are gradually exposed to this terrifying atmosphere as we approach graduation and it is most frightening because our role models are the actual professors whose professions are governing them, not vice versa. Achieving and maintaining physical fitness us only a single aspect of life, but, while providing a fruitful experience in itself, it also supplies an extremely potent adjuvant to all out daily activities, thus providing a more versatile and enjoyable existence. 